\title{
Dynamic Modeling and Simulation of Double-Planetary Gearbox Based on Bond Graph
}

\author{
Wuzhong Tan, ${ }^{1,2}$ Jiangming Wu $\left(\mathbb{D}^{1},{ }^{1}\right.$ De Ni, ${ }^{2}$ Hongzhi Yan $\mathbb{D}^{1},{ }^{1}$ Enming Xiang, \\ and Shuangqi Liu ${ }^{1}$ \\ ${ }^{1}$ School of Mechanical and Electrical Engineering, Central South University, Changsha 410083, China \\ ${ }^{2}$ AECC Hunan Aviation Powerplant Research Institute, Zhuzhou, Hunan 412002, China \\ Correspondence should be addressed to Jiangming Wu; 1752398990@qq.com
}

Received 23 April 2021; Accepted 15 October 2021; Published 5 November 2021

Academic Editor: Omar Naifar

Copyright (C) 2021 Wuzhong Tan et al. This is an open access article distributed under the Creative Commons Attribution License, which permits unrestricted use, distribution, and reproduction in any medium, provided the original work is properly cited.

\begin{abstract}
New generations of powertrains are using gearboxes with multiple speed-shift designs to improve fuel efficiency. However, transmission controls and calibration are substantially time consuming, specifically during shift processes. To study the dynamic characteristics of a gearbox with a double-planetary gear train and analyze the influence of external excitation and internal parameters on the dynamic response of a system, dynamic modeling and simulation of the transmission system are conducted. Some physical processes are complex and difficult to express via lumped mass modeling. The dynamic model of a double-planetary gearbox is obtained by adopting the bond graph method based on the working principle analysis of the transmission, as well as the kinematic characteristics of the double-planetary gear train. Subsequently, state equations are deduced from the dynamic model of the power transmission system for simplified calculations, which can effectively facilitate the shift process simulation. The basic case of different shift plans and times is originally analyzed, followed by an analysis of the influence of damping, stiffness, and moment of inertia on transmission systems. The analysis results provide references for the structural design, control strategy optimization, and failure diagnostics of this gearbox type.
\end{abstract}

\section{Introduction}

A gearbox is a mechanical system with multiple degrees of freedom that is generally equipped with a gear train, bearings, transmission shaft, clutch, and brake. Compared with conventional gear transmissions, planetary gear transmission systems have several unique advantages. As its most significant advantage, a planetary gear can split power when transmitting power, while its input and output shafts lie on the same horizontal line. Therefore, planetary gear transmission systems have been widely used in different types of speed reducer, speed increaser, and speed changer systems. Owing to the enhancement of transmission-shifting continuity and smoothness requirements, as well as the utilization of composite-planetary gear train and its integrated parts, its structure has become more compact and complex, and the analysis of its dynamic characteristics has become more difficult. The availability of a reliable power train model provides a basis for different simulation studies of power trains and facilitates the development of various power train estimation and control strategies. Therefore, an efficient and accurate dynamic analysis method is required to address the problem triggered by the complex dynamic analysis process of transmission. Because controlling the shifting process of transmission involves clutch control, as well as the general control of the clutch by a hydraulic system, the shifting process of the transmission involves multiple energy fields. Regarding the analysis of system dynamics with multiple energy fields, the bond graph theory proposed by American scholar H. M. Paynter is applicable to the nonlinear dynamic load system with multiple inputs and outputs.

A conventional control-oriented power train model comprises dominant transmission dynamics that are characterized by gear inertias, speed ratios, and clutch friction. Other effects, such as transmission backlash and friction, 
compliance of engine mounts, clutch drag, and viscous clutch friction dynamics, are usually neglected.

A previous study [1] adopted the direct-oriented vector control model to study the power change in variable speed wind turbine systems, and according to the requirements of mechanical speed control, it conducted research on control strategy [2] and the development of robust software sensor for the online estimation of stator resistance [3]. Ranogajec and Deur [4] presented an automated model-order reduction method in which the corresponding bond graph model was constructed based on a general example of a ten-speed advanced transmission system, which comprised four planetary gears and six clutches. In the research conducted by $\mathrm{Hu}$ et al. [5] on the power flow and transmission efficiency of a transmission system, the constraints between the components were analyzed based on the energy conservation and power flow characteristics of the system. The dynamics of the dual-planetary platoon-power coupling mechanism has been modeled and simulated via the bond graph method. For example, the dynamic modeling of a dual-planetary gear train was included in a study conducted by Zhongshuang and Weike [6], which adopted augmentation to effectively eliminate the differential causality in the vector bond graph model of this system type. In the research by Lin et al. [7], the bond graph model of a coaxial dualoutput reducer was established, and the variation law of internal variables with time was obtained. The response curves of two output shaft speeds were compared under different parameters, and the influence of each parameter on the dynamic characteristics of the system was analyzed. A standard modeling process was proposed for the planetary gearbox modeling of complex vehicles based on the bond diagram theory proposed by Li and Wang [8]. The gearbox system was decomposed into three subsystems: a planetary gear train, clutch, and inertial rotor. The corresponding dynamic model was constructed and analyzed based on a given sample model. The bond graphs and differential equations were also utilized in the process adopted in a model described by Liang et al. [9]. In addition, 20-sim simulation software was used to power bond the single drive and complete loops of the RV reducer graph model for simulation analysis. However, in the study of gearbox control and fatigue analysis, gearbox transmission is usually considered as a one-dimensional problem. Here, it is unnecessary to use a vector bond graph, which may consume extra computational resources in the simulation. However, the complexity of gearbox dynamic modeling increases exponentially with the number of gears. The causality definition of power bond in the bond graph theory complicates the system modeling process. Owing to different manufacturers, several differences exist in the schematic design of the gearbox. The causality definition for power bonds in the bond graph theory also complicates this system modeling process.

A transmission is a planetary gear-clutch system that can generate multi-gear output speeds with multiple power transmission paths involving different amounts of energy. In this study, a one-way clutch transmission system for a dualplanetary gear train-friction clutch was adopted as the research object. To provide a basis for improving the basic dynamic model, a systematic analytical and simulation analysis of the shift dynamics was conducted in this study.

In this paper, the fundamental structure and working principle of the dual-planetary gearbox are analyzed, and the bond graph method is adopted to establish the corresponding full-gear set model. The state equations of the transmission system are derived, and the time-domain curves of key variables, such as speed and torque, are obtained under different load conditions via numerical solutions. The impact of different working states of the motor and engagement modes of the clutch on the system response are also discussed. The influence of the main factors, such as system damping, comprehensive stiffness, and moment of inertia, on the system dynamic response are analyzed.

\section{Basic Principle of Double-Planetary Gearbox}

2.1. Structure and Working Principle. Transmission systems that incorporate composite-planetary gear systems have been widely used in various transportation tools. Owing to the differences between the application environment and the working conditions, the design and shift mode of the transmission chain are different. Presently, there are several open research data on the transmission system, including the design of a double-input planetary differential transmission configuration, fixed-shaft star-type variable speed configuration [10], axial double-star idler gear configuration [11], clutch-free wheel variable speed configuration [12], and clutch-differential gear train variable speed configuration [13]. The transmission primarily comprises the combination of a gear train and clutch, with advantages and disadvantages in its practical application. When selecting the right gearbox for a mechanical system, it is important to consider the matching degree between the entire vehicle layout and gearbox design, including the rationality analysis of the transmission's working mode. The transmission investigated in this study is a one-way clutch transmission system for double-planetary gear train friction clutches. Figure 1 presents the three-dimensional drawing and the principal scheme of a gear set for a doubleplanetary gearbox.

The gear set consists of a double-planetary gear, which comprises a sun gear, ring, carrier, and two sets of planet gears. The one-way clutch is installed between the input stage of the planetary carrier and gearbox, and its reaction torque is transferred to the engine block, which is connected to the frame by elastic engine mounts. The input and the output ends of the friction clutch are integrated with the ring gear and carrier, respectively. The input torque of the gear set enters the system from the sun gear, while the output torque is transmitted to the output shaft by the gear ring using the spline. The oil jet is arranged on the gearbox to lubricate the gear train, and the lubricating and the hydraulic oils of the friction clutch are introduced from the internal lubricating oil circuit of the output end.

By adjusting the hydraulic system, the engagement and disengagement of the friction clutch can be controlled to facilitate the shifting process of the transmission, which 


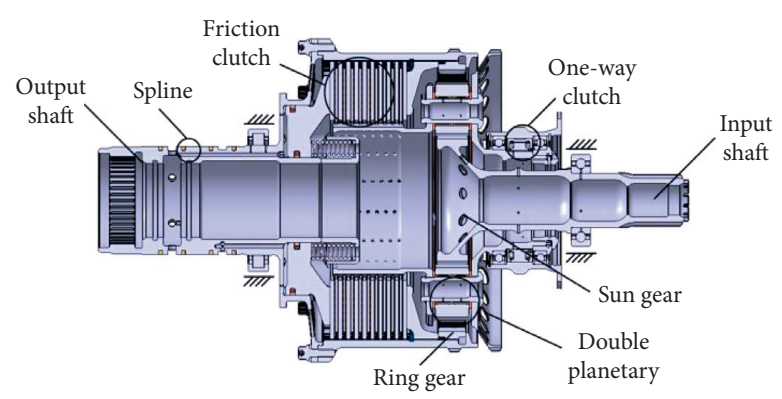

(a)

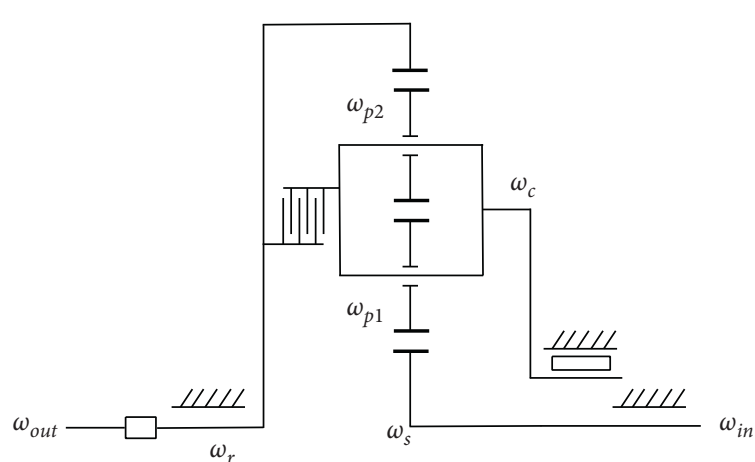

(b)

FIgURE 1: Double-planetary gearbox. (a) Three-dimensional drawing. (b) Structure diagram.

ensures completion of the power transmission matching between the power source and transmission under different working conditions. Under a low-speed gear condition, the friction clutch is off, and the carrier is in reverse rotation; however, the one-way clutch acts on the planet carrier to terminate this phenomenon. Hence, the speed of the carrier is zero in the low gear. At this point, the planetary gear system is equivalent to the single-degree-of-freedom gear system fixed by the carrier. When the system needs to switch from low to high gear, the hydraulic system commences its operation, the friction clutch is engaged, and the one-way clutch switches to the overrunning state during the friction clutch engagement process. Furthermore, the inner ring rotates freely, and the outer ring is fixed to the housing. After the clutch is engaged, the gear ring and carrier exhibit the same speed, and no relative rotation exists in the planetary gear system. At this point, instead of rotating, all the planet wheels are in revolutions. In addition, the output shaft speed is the same as the input shaft speed, and the upshift process ends.

\subsection{Kinematic Analysis of Double-Planetary Gear Train.} To simplify the analysis, the sun and ring gears with input and output shafts, respectively, are regarded as separate parts, and the kinematic analysis of the double-planetary gear system is performed accordingly. The schematic diagram of the motion relationship for the dual-planetary gear train is presented in Figure 2. Kinematic equations can be drawn from Figure 2 as follows.

At the meshing point, the linear velocities of the ring gear $R$ and planetary pinion $P 2$ are equal; accordingly:

$$
\begin{aligned}
\omega_{r 1} & =\omega_{r}-\omega_{c}, \\
\omega_{p 2} r_{p 2} & =\omega_{r 1} r_{r} .
\end{aligned}
$$

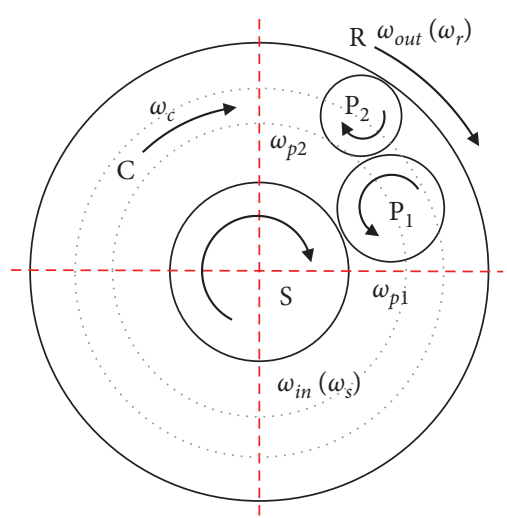

FIGURE 2: Motion relationship diagram of double-planetary gear train.

Similarly, for the planetary gears $P 1$ and sun gear $S$, as well as the planetary gear $P 1$ and planetary pinion $P 2$, the following equations are also satisfied:

$$
\begin{aligned}
\omega_{s 1} & =\omega_{s}-\omega_{c}, \\
\omega_{p 1} r_{p 1}+\omega_{s 1} r_{s} & =0, \\
\omega_{p 1} r_{p 1}+\omega_{p 2} r_{p 2} & =0,
\end{aligned}
$$

where $\omega_{r 1}$ and $\omega_{s 1}$ denote the relative speeds of the ring and sun gears, respectively, together with their carriers. The basic characteristic equation of the planetary gear train with double planetary gears is

$$
\omega_{s}-\beta \omega_{r}-(1-\beta) \omega_{c}=0 .
$$

Different working modes are analyzed: in low gear, the system is a fixed-shaft gear train, and the equations $\omega_{c}=0$ and $\omega_{\text {out }}=\omega_{\text {in }} / \beta$ are satisfied; in high gear, because there is no relative rotation between the sun gear, ring gear, and 
carrier, it is assumed that the system is equivalent to a rigid body without relative rotation, such that $\beta=1$, and the output speed $\omega_{\text {out }}$ is equal to the input speed $\omega_{\text {in }}$.

\section{Bond Graph Model of Double- Planetary Gearbox}

3.1. Establishment of Bond Graph Model. The bond graph method can combine different energies in a dynamic analysis model and does not require separate analyses of different energy systems, which makes the system modeling process more compact and smoother [14]. Bond graphs have been applied in several fields, such as mechanical systems $[15,16]$, fault detection [17, 18], power transfer [19], and bionic design [20]. A dual-planetary gearbox is a single-input, single-output system that switches the working mode using a friction clutch, including different forms of energy exchange and flow. Planetary gear trains, also known as epicyclic gear trains, are key elements of a transmission gearbox. Owing to the combination of the self- and center-following rotations of the planetary gear while the carrier rotates, it is difficult to model planetary gear trains. However, the bond graph method provides a feasible approach to modeling planetary gear trains.

Based on the analysis of the structure and the working principle of the double-planetary gearbox, a " 1 " node is established for each absolute and relative speed in the corresponding bond graph model; considering the meshing stiffness of the gear pair and torsional stiffness of the shaft, a "TF" converter and "0" node are added between the "1" nodes with a connection relationship to represent the capacitive elements of meshing and torsional stiffness. " $C$ " is set at the corresponding equal force connection node " 0 ." The power flow direction is indicated according to the kinematic relationship between the transmission parts and internal power path. Considering the moment of inertia of each component, the inertial element " $P$ " and potential source " $S_{e}$ " are set on the "1" node with absolute velocity. The rotational damping of gears, one-way and friction clutches, input effort source " $S_{e}$ " or flow source " $S_{f}$ " and resistive element " $R$ " are set on " 1 " node. According to the causal relationship of elements, the power flow direction of the system is achieved. The full-order bond graph model of the gearbox is established, as illustrated in Figure 3. The corresponding meanings of each element in the bond graph model are presented in Table 1 .

Because the torque change time of the one-way clutch is extremely short during the shifting process, the model is simulated by adjusting the rotation damping of the carrier.

\subsection{Calculation of the Component Parameters of the Bond Graph}

3.2.1. Meshing Stiffness. Gear meshing stiffness is related to many factors, such as gear parameters, wheel body design, normal load, machining accuracy, and material selection. Generally, meshing stiffness can be addressed by the mechanics of the materials, elasticity, and numerical methods. Although finite element simulation technology is often adopted in nonlinear dynamic analysis, it requires a computer to complete

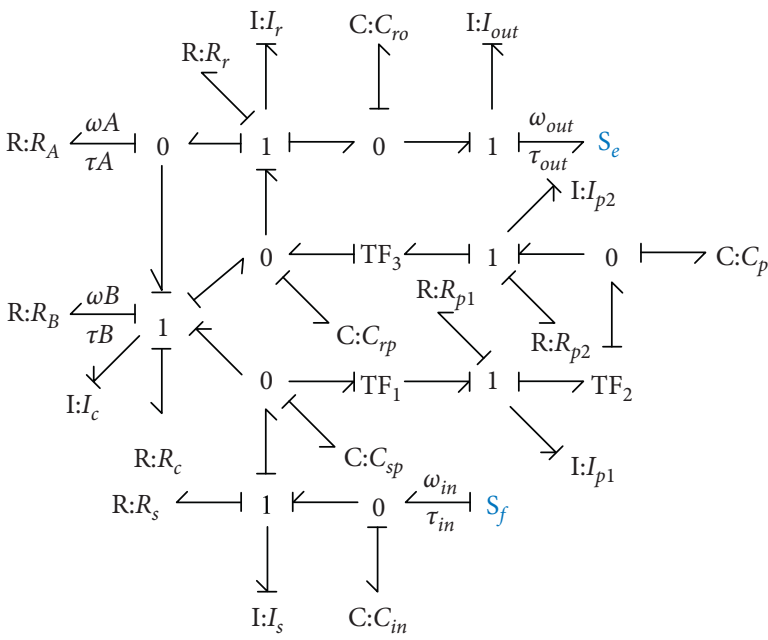

FIGURE 3: Bond graph model of double-planetary gearbox.

the severely complex calculation process, and its analysis process is unclear. Therefore, the meshing stiffnesses in this bond graph model are calculated by utilizing the material mechanics method in the industry standard, as well as the meshing stiffness determination method in the current $\mathrm{GB} / \mathrm{T}$ 3480.1-2019. The formula for the meshing stiffness $k_{m}$ is expressed as

$$
\begin{aligned}
k_{m} & =c^{\prime}\left(0.75 \varepsilon_{\alpha}+0.25\right), \\
c^{\prime} & =c_{t h}^{\prime} C_{M} C_{R} C_{B},
\end{aligned}
$$

where $\dot{c}_{t h}, C_{M}, C_{R}, C_{B}$, and $\varepsilon_{\alpha}$ represent the theoretical single pair tooth stiffness, theoretical correction coefficient, wheel structure coefficient, basic rack coefficient, and end face coincidence, respectively. The torsional stiffness can be obtained by converting the displacement of the meshing point along the meshing line into the torsional angle displacement of the meshing point along the circumferential direction: $K_{g}=k_{m} r_{b}^{2}$, where $r_{b}$ denotes the radius of the base circle. In the bond graph theory, the reciprocal of the capacitive element $C$ corresponds to the torsional stiffness $C=1 / K_{g}$, and the characteristic equation is expressed as

$$
e=\frac{q}{C}
$$

where $e, q$, and $C$ denote the torque acting on the part, angular displacement, and flexibility, respectively.

3.2.2. Moment of Inertia. Owing to the detailed structure of the parts in the configuration, there are multiple dimensional parameters. The conventional mathematical calculation method cannot accurately solve the moment of inertia of the parts; hence, the moment of inertia of the parts is directly obtained by utilizing the finite element software. In the bond graph theory, the inertia element $I$ is adopted to simulate the moment of inertia. The characteristic equation is expressed as

$$
f=\frac{p}{I}
$$


TABle 1: Meaning of each component in the bond graph model.

\begin{tabular}{|c|c|}
\hline Components & Meanings \\
\hline$S_{f}, S_{e}$ & and effort sources on input and ob \\
\hline$C_{\mathrm{in}}, C_{r o}, C_{s p}, C_{p}, C$ & $\begin{array}{l}\text { Flexibility relative to torsional stiffness of input shaft, torsional stiffness } \\
\text { sun gear and planetary gear } P 1 \text {, meshing stiffness between planetary gea } \\
\text { stiffness between planetary gear } P 2 \text { and ring }\end{array}$ \\
\hline$I_{s}, I_{p 1}, I_{p 2}, I_{c}, I_{r}, I_{\text {out }}$ & $\begin{array}{c}\text { Moments of inertia of sun gear (including the input shaft), planetary gear } P 1 \text {, planetary pinion } P 2 \text {, carrier } C \text {, ring } \\
\text { gear } R \text {, and output shaft, respectively }\end{array}$ \\
\hline $\begin{array}{l}R_{s}, R_{p 1}, R_{p 2}, R_{r}, R_{A} \\
R_{B}\end{array}$ & $\begin{array}{c}\text { Rotation damping of sun gear, planetary gear } P 1 \text {, planetary pinion } P 2 \text {, ring gear } R \text {, friction clutch, and one-way } \\
\text { clutch, respectively }\end{array}$ \\
\hline $\mathrm{TF}_{1}, \mathrm{TF}_{2}, \mathrm{TF}_{3}$ & Converter related to the number of teeth of the meshing gear and the meshing type \\
\hline
\end{tabular}

where $f, p$, and $I$ represent the rotating speed of the part's rotation, generalized momentum (the integral of the torque relative to time), and moment of inertia of the gears and shafts, respectively.

3.2.3. Rotational Damping. The gearbox contains multiple gears and shafts; therefore, the influence of the rotation damping of the gears and shafts on the system must be considered. In the bond graph theory, the rotation damping can be simulated by the resistive element $R$, and its characteristic equation is expressed as

$$
e=R f \text {. }
$$

3.2.4. Torsional Stiffness. In the dual-planetary gearbox, the input shaft and sun gear are designed on the same part. Here, the torsional stiffness of the input shaft and the meshing stiffness of the sun gear are calculated separately. The internal gear ring is connected to the output shaft through splines, while the torsional stiffness of the output shaft and the meshing stiffness of the gear ring are required to be calculated separately. According to the theory of material mechanics, the torsional stiffness of the shaft is expressed as

$$
k_{s}=\frac{\mathrm{GI}_{s}}{l_{s}}
$$

where $G, I_{s}$, and $l_{s}$ denote the shear elastic modulus of the material, moment of inertia of the shaft, and torsion length of the shaft, respectively.

3.3. Friction Clutch Torque Model. The method presented in the literature [21] is adopted to develop the friction clutch torque model, which was developed to satisfy the conditions of causality and ensure that the directions of the friction torque on the active (ring gear) and driven (carrier) ends of the clutch are consistent. The torque calculation equation is expressed as

$$
\tau_{A}= \begin{cases}K_{f}\left[\omega_{r}-\omega_{c}+\tau\left(\dot{\omega}_{r}-\dot{\omega}_{c}\right)\right] & \left|\omega_{r}-\omega_{c}\right|>\Delta \omega, \\ T_{s} & \left|\omega_{r}-\omega_{c}\right| \leq \Delta \omega .\end{cases}
$$

According to the torque form calculation formula, the bond graph form of the " 0 " node connected to the " $R$ " element is adopted to elucidate equation (12), as illustrated in Figure 3. In the simulation process, the torque transmission is calculated by the rotating speed and acceleration of the active and the driven ends, while the torque transmission is controlled by adjusting the $K_{f}$ value. In this torque model, the clutch is controlled by the $K_{f}$ value. If $K_{f}=0$, it implies that the clutch is disengaged. When the clutch is engaged, the value of $K_{f}$ should be constant. When the speed difference between the driving and driven ends is within a certain range, the friction clutch torque is determined by the external torque $T_{s}$.

3.4. One-Way Clutch Torque Model. The structural characteristics of the one-way clutch restrict its rotation in one direction, and the resistance encountered when rotating in the other direction is negligible. In the dual-planetary gearbox, the outer ring of the one-way clutch is bonded with the housing, while the inner ring bonds with carrier $C$. The one-way clutch is modeled as a nonlinear spring with discontinuous stiffness. Here, the mathematical model of the one-way clutch is an angular displacement difference model, and the torque $\tau_{B}$ expressions for the one-way clutch are presented as follows:

$$
\tau_{B}= \begin{cases}K_{o} \theta_{c}+C_{o} \dot{\theta}_{c} & \theta_{c}>0 \\ 0 & \theta_{c} \leq 0\end{cases}
$$

where $\theta_{c}$ denotes the angular displacement of carrier $C$. Because the housing is assumed to be completely fixed, it is solely necessary to ascertain the state of the one-way clutch according to the angular displacement.

\section{State Equations of the System}

Because the dual-planetary gear transmission system is an epicyclic gear train, the effort variables and flow variables in the bond graph model correspond to the torque and rotating speed in the system. According to the causality of the elements in the bond graph model, the inertial and capacitive elements in the independent states are obtained, and the corresponding generalized momentum $p$ and displacement $q$ are adopted as state variables. In the mechanical rotation system, $p$ is the angular momentum, $q$ denotes the angular displacement, the corresponding potential $e$ represents the torque, the flow $f$ is the rotating speed, and the subscripts represent different parts or connections. The state variables of the system are expressed as

$$
\mathbf{X}=\left[\begin{array}{lllllllllll}
q_{\text {in }} & p_{s} & p_{c} & q_{s p} & p_{p 1} & q_{p} & p_{p 2} & q_{r p} & p_{r} & q_{r o} & p_{\text {out }}
\end{array}\right]^{T} .
$$


Input variable:

$$
\mathbf{U}=\left[\begin{array}{llll}
s_{f} & s_{e} & \tau_{A} & \tau_{B}
\end{array}\right]^{T} .
$$

According to the causal relationship and power flow direction in the bond graph, the relationship between the system state variables can be obtained using the equations of state:

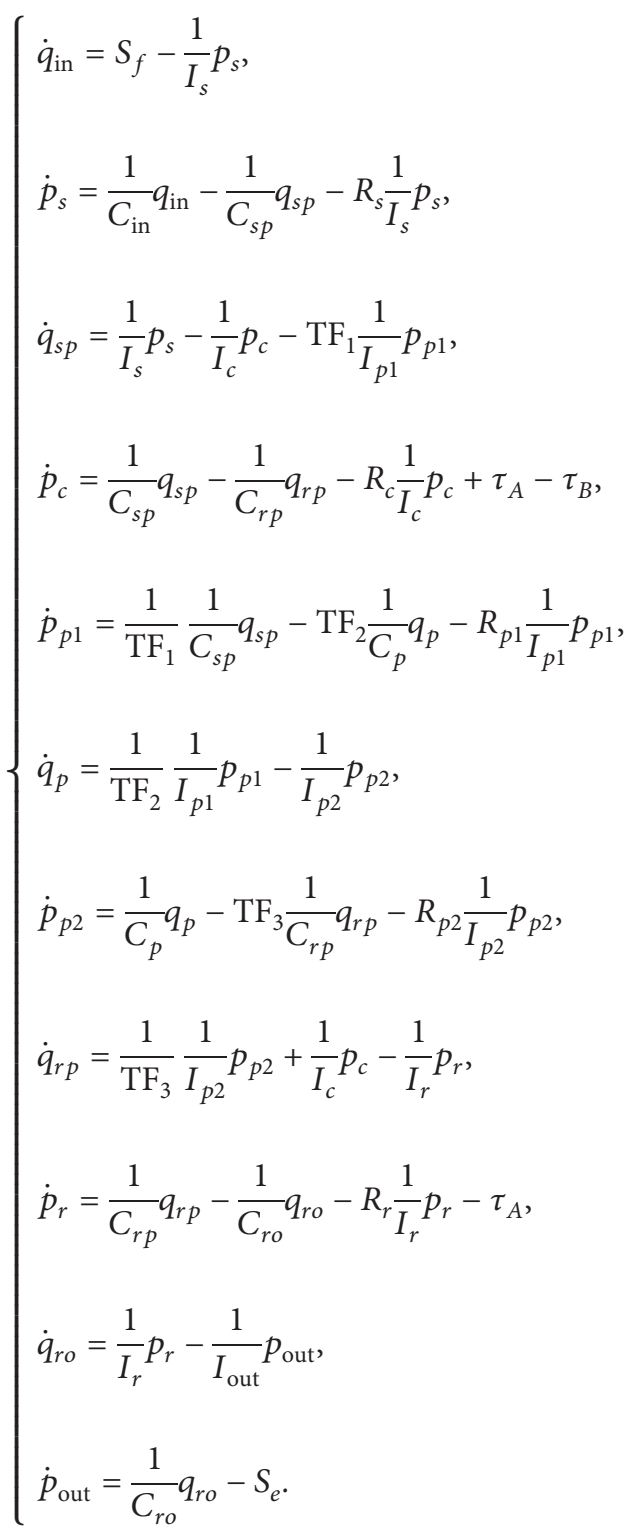

The left side of the equations is the derivative of the generalized momentum $p$ of the inertial element and the generalized displacement $q$ of the capacitive element. On the right, we present the relational formula derived from the power flow direction of each key of the node, where the inertial and capacitive elements are located, as well as the balance between the effort and flow. According to the physical quantities represented by the components and the relationship between the ports of each node, the system's state-space equations of the full-order bond graph model for the double-planetary gear transmission system can be obtained as

$$
\dot{X}=\mathbf{A} X+\mathbf{B} U
$$

where $\mathbf{A}$ is an 11-order matrix that contains all the coefficients of the state variables on the right side of equation (15), while $\mathbf{B}$ is a matrix comprising the coefficients of the input variables on the right side of equation (15).

In the low gear, the friction clutch is disengaged, the oneway clutch is engaged, and the carrier and housing have no relative rotation. Then, node " 1 " corresponding to the carrier and related components in the full-order bonding graph is removed, the reduced-order bond graph model of the low gear state is obtained (Figure 4), and the state variables and state-space equations of the system are obtained at low speed.

State variables:

$$
X_{L}=\left[\begin{array}{llllllllll}
q_{\text {in }} & p_{s} & q_{s p} & p_{p 1} & q_{p} & p_{p 2} & q_{r p} & p_{r} & q_{r o} & p_{\text {out }}
\end{array}\right]^{T} .
$$

State equations:

$$
\begin{aligned}
& \int \dot{q}_{\text {in }}=S_{f}-\frac{1}{I_{s}} p_{s}, \\
& \dot{p}_{s}=\frac{1}{C_{\text {in }}} q_{\text {in }}-\frac{1}{C_{s p}} q_{s p}-R_{s} \frac{1}{I_{s}} p_{s}, \\
& \dot{q}_{s p}=\frac{1}{I_{s}} p_{s}-\mathrm{TF}_{1} \frac{1}{I_{p 1}} p_{p 1}, \\
& \dot{p}_{p 1}=\frac{1}{\mathrm{TF}_{1}} \frac{1}{C_{s p}} q_{s p}-\mathrm{TF}_{2} \frac{1}{C_{p}} q_{p}-R_{p 1} \frac{1}{I_{p 1}} p_{p 1}, \\
& \dot{q}_{p}=\frac{1}{\mathrm{TF}_{2}} \frac{1}{I_{p 1}} p_{p 1}-\frac{1}{I_{p 2}} p_{p 2}, \\
& \dot{p}_{p 2}=\frac{1}{C_{p}} q_{p}-\mathrm{TF}_{3} \frac{1}{C_{r p}} q_{r p}-R_{p 2} \frac{1}{I_{p 2}} p_{p 2}, \\
& \dot{q}_{r p}=\frac{1}{\mathrm{TF}_{3}} \frac{1}{I_{p 2}} p_{p 2}-\frac{1}{I_{r}} p_{r}, \\
& \dot{p}_{r}=\frac{1}{C_{r p}} q_{r p}-\frac{1}{C_{r o}} q_{r o}-R_{r} \frac{1}{I_{r}} p_{r}, \\
& \dot{q}_{r o}=\frac{1}{I_{r}} p_{r}-\frac{1}{I_{\text {out }}} p_{\text {out }}, \\
& \dot{p}_{\text {out }}=\frac{1}{C_{r o}} q_{r o}-S_{e} .
\end{aligned}
$$




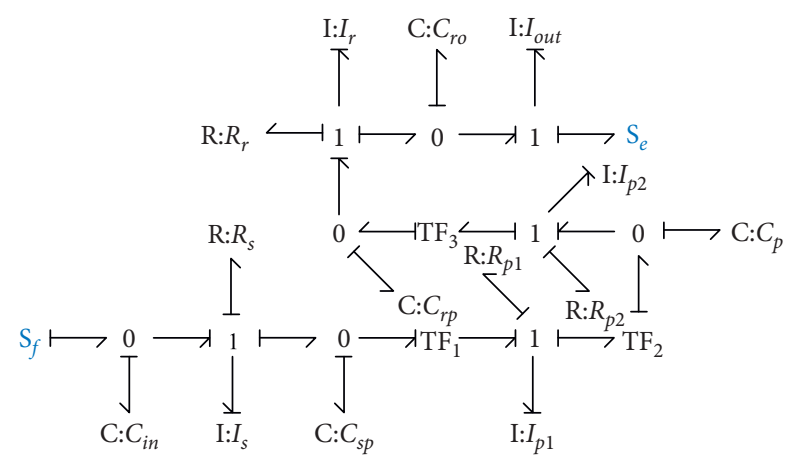

Figure 4: Bond graph model of low gear for dual-planetary gear transmission.

Similarly, the state-space equations of the system in the high gear state can be obtained according to the physical quantities represented by the components and the relationship between the ports of each node. This step will not be repeated here. In the high gear state, the carrier and ring gear maintain the same rotating speed, the planetary gear $P 1$ and planetary pinion $P 2$ do not rotate, and the input and output shafts can be regarded as a fixed connection.

\section{Analysis of System Dynamic Simulation}

5.1. System Dynamic Simulation. Table 1 shows the corresponding relationship between the components in the bond graph and the power variables in the gearbox, according to the state equations of the dual-planetary gearbox, the torsional stiffness, rotational damping, and moment of inertia, other parameters are introduced into the bond graph model. The main parameters of the dual-planetary gear train are presented in Table 2.

A mathematical model based on the bond graph model is established in MATLAB, and specific parameters adopted in the simulation are presented in Table 3 . The Simulink scheme based on the bond graph is presented in Figure 5, and the Runge-Kutta method is used to numerically solve the model. The change curve of the sun gear, planetary gear, planetary pinion, rotating speed of the carrier, and rotating speed of the output shaft is obtained with time, as illustrated in Figure 6.

In Figure 6, it can be observed that the rotating speed of multiple parts varies in the starting and upshifting process in the low gear state. From the starting to steady state, the rotating speed of the sun gear, planet gear, planet pinion gear, and output shaft tends to be stable after different vibration periods, which reflect the rotating speed of the system response. Significant differences exist in the speed vibration of different parts. There is a fixed connection between the ring gear and gearbox; hence, the rotating speed is zero. In the stable state of low gear, the speeds of the sun gear, planetary gear, planetary pinion gear, and output shaft are approximately $628,1615,1785 \mathrm{rad} \cdot \mathrm{s}$, and $314 \mathrm{rad} / \mathrm{s}$, respectively, and upshift commences at $10 \mathrm{~s}$. The curve change trend in Figure 6 shows that the system completes the shift process after approximately $2 \mathrm{~s}$, and no significant vibration and overshoot exist in the speed curve of the components during the shift process. During the upshift process, the
TABle 2: Parameters of double-planetary gear train.

\begin{tabular}{lcc}
\hline Parameter & Value & Unit \\
\hline$N_{s}$ & 108 & - \\
$N_{p 1}$ & 42 & - \\
$N_{p 2}$ & 38 & - \\
$N_{r}$ & 216 & - \\
$m$ & 1.75 & $\mathrm{~mm}$ \\
$I_{s}$ & 0.3 & $\mathrm{~kg} \mathrm{~m}^{2}$ \\
$I_{p 1}$ & 0.002 & $\mathrm{~kg} \mathrm{~m}^{2}$ \\
$I_{p 2}$ & 0.005 & $\mathrm{~kg} \mathrm{~m}^{2}$ \\
$I_{r}$ & 0.5 & $\mathrm{~kg} \mathrm{~m}^{2}$ \\
$I_{c}$ & 0.4 & $\mathrm{~kg} \mathrm{~m}^{2}$ \\
$I_{\text {out }}$ & 4 & $\mathrm{~kg} \mathrm{~m}^{2}$ \\
\hline
\end{tabular}

TABLE 3: Numerical simulation parameter settings.

\begin{tabular}{lccc}
\hline Subsystem & Parameter & Value & Unit \\
\hline \multirow{4}{*}{ Double-planetary gear } & $S_{f}$ & 628 & $\mathrm{rad} / \mathrm{s}$ \\
& $\mathrm{S}_{e}$ & $955 / 1423.5$ & $\mathrm{Nm}$ \\
& $K_{g}$ & 280000 & $\mathrm{Nm} / \mathrm{rad}$ \\
\multirow{2}{*}{ Shafts } & $C_{g}$ & 20 & $\mathrm{Nm} \cdot \mathrm{s} / \mathrm{rad}$ \\
\hline \multirow{2}{*}{ Friction clutch } & $K_{\text {in }}$ & 55000 & $\mathrm{Nm} / \mathrm{rad}$ \\
& $K_{\text {out }}$ & 10000 & $\mathrm{Nm} / \mathrm{rad}$ \\
\hline \multirow{2}{*}{ One-way clutch } & $K_{f}$ & 100000 & $\mathrm{Nm} \cdot \mathrm{s} / \mathrm{rad}$ \\
& $\tau$ & 0.1 & $\mathrm{~s}$ \\
\hline
\end{tabular}

speeds of the planetary gear and planetary pinion decrease to zero, and the rotating speed of the carrier increases to the same speed as that of the output shaft. Under the stable state of the high gear state, the input and output shafts are at the same rotating speed of approximately $628 \mathrm{rad} / \mathrm{s}$. From the above results, it can be inferred that the transmission ratios of the low and high gears are 2 and 1, respectively, and the rotating speeds of the sun, planetary, planetary pinion, and ring gears in the low gear state satisfy the kinematic characteristic equation of the double-planetary gear train. Based on the above analysis, it can be verified that the calculation result of the bond graph model is consistent with the transmission ratio of a double-planetary gearbox.

\subsection{Influence of External Excitation on the Dynamic Response}

5.2.1. Input Power. In the transmission system, the motor usually transmits power to the input end of the gearbox via the torque converter. During the shift process, the output power of the motor is usually adjusted to match the shift process of the gearbox to ensure the stability of the output, as well as the smoothness of the shift. In the simulation process, two types of gear shifting schemes, Schemes A and B, are designed. Scheme A ensures that the input speed and torque remain unchanged before gear shifting. As the gear shifting process progresses, the output power of the motor is increased, and the output power of the motor reaches a stable state after gear shifting. Scheme B ensures that the input speed of the gearbox remains unchanged before gear shifting, adjusts the input torque, reduces the output power of the motor to a certain value, and then starts the upshift 


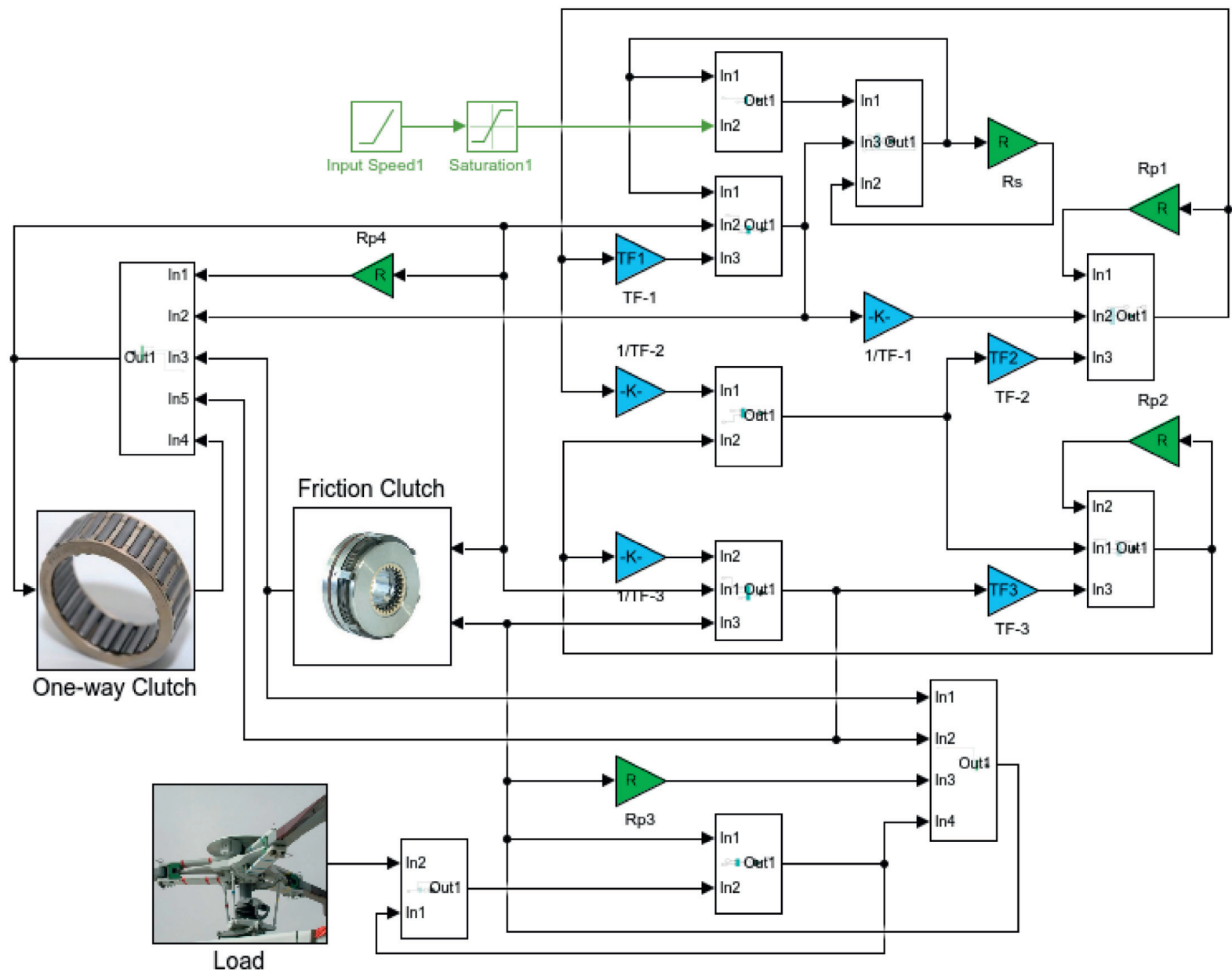

Figure 5: Simulation scheme using MATLAB Simulink for double-planetary gearbox shift model validation.

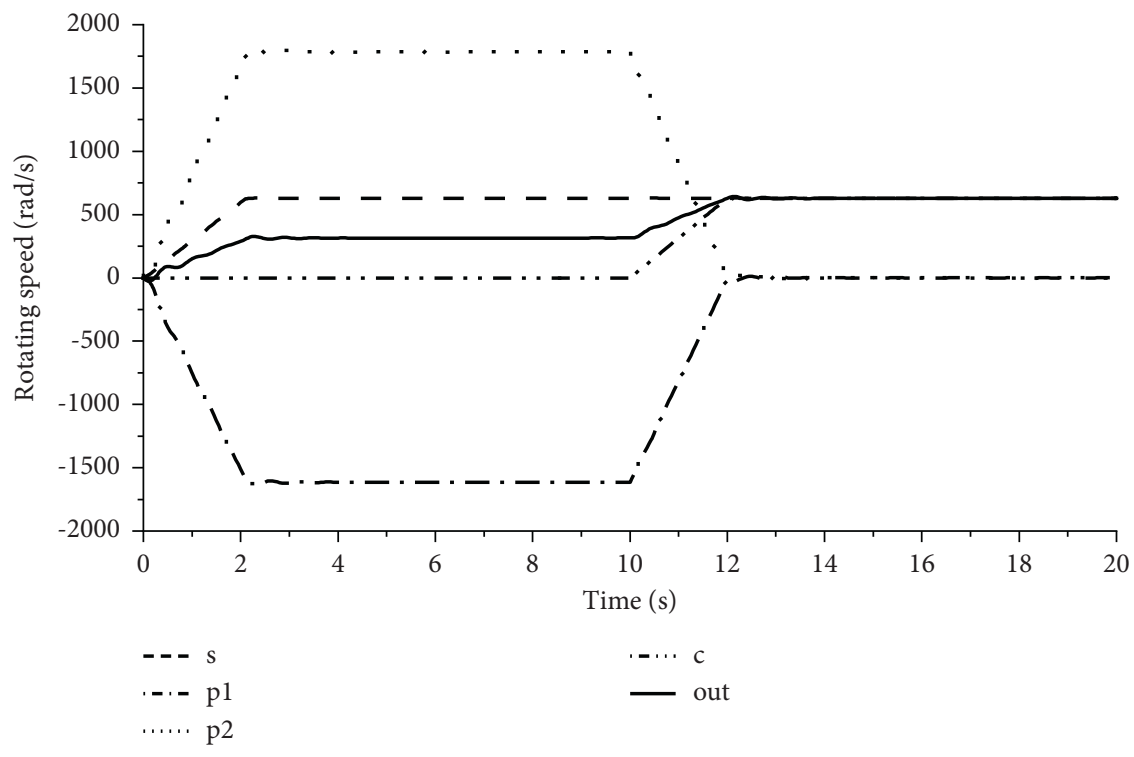

FIGURE 6: Simulation responses of launch/shift engagement. 
process. At the end of the upshift process, the output torque of the motor reaches a stable value. Figures $7(a)$ and $7(b)$ present the change curves of the input torque and output speed before and after shifting under constant power (Scheme A) and variable power (Scheme B) modes, respectively.

Figure 7 shows that the speed of the output shafts in the two shift modes are stable at approximately $314 \mathrm{rad} / \mathrm{s}$ and $628 \mathrm{rad} / \mathrm{s}$ after launching and upshifting, respectively. The change in the output shaft rotating speed is consistent, while the change in the motor power does not influence the change rule of the output speed. This is because the motor maintains a constant speed before and after shifting and solely adjusts the output torque. However, the input torque curve is substantially different. In Scheme A, the output torque of the motor gradually increases with the launch of the upshift process, which is a nonlinear upshift mode with significant vibrations. In Scheme B, the output power of the motor starts to decrease linearly before shifting and then starts the upshift process after reaching the preset point of power. As the gear up process progresses, the output power of the motor evidently increases linearly. Therefore, the control mode similar to Scheme A can be adopted under the low requirement conditions for motor torque variation, which has a low requirement for the design of the control system. Conversely, in the case of high requirements for input torque change, it is suggested that the control mode similar to Scheme B is adopted, as it can control the shift torque more accurately.

5.2.2. Gear Shift Time. The clutch is usually used to break components or consolidate two components in the transmission system, such that the kinematic relationship of the gear train in the transmission is altered. This is done to adjust the transmission ratio and to realize the vehicle launching, parking, and shifting processes. The clutch engagement time directly affects the dynamic characteristics of the entire vehicle during the launch, park, and shift. For the double-planetary gearbox, the effect of upshift time on the output speed of the transmission is studied. Under the condition of keeping other parameters unchanged, the changes in the output shaft rotating speed under the shift times of $0.5 \mathrm{~s}, 1 \mathrm{~s}$, and $2 \mathrm{~s}$ are determined. The simulation results are presented in Figures 8 and 9.

Figure 8 depicts that the vibration of rotating speed reaches the peak value at the moment when the clutch completes its engagement under three shift durations. Therefore, under shift durations of $0.5 \mathrm{~s}, 1 \mathrm{~s}$, and $2 \mathrm{~s}$, the peak value of rotation fluctuation is $6.8 \%, 4.7 \%$, and $2.4 \%$ of the stable speed, respectively. Figure 9 demonstrates that the acceleration reaches the maximum value during the upshift, and the shift time decreases with an increase in the higher the peak acceleration. This is owing to the change triggered by the dynamic friction torque to static friction torque in the clutch torque transmission process. The former is primarily related to clutch hydraulic pressure, while the latter is completely influenced by external torque. Figures 8 and 9 depict that with a decrease in the upshift time, the vibration amplitudes of the output speed and acceleration increase, including the vibration frequency. When the upshift time becomes longer, the amplitude and frequency of the output speed and acceleration vibration decrease and then tend to be stable, which are more conducive to the stability of the system. However, the longer the upshift time, the longer the engagement process of the friction clutch and the greater the heat generated by the friction plate, which triggers more energy loss and reduces the transmission efficiency of the system. Therefore, the shift time or speed smoothness cannot be considered as the sole index influencing shift design. It is necessary to comprehensively consider the influence of different aspects and then adjust and optimize the shift strategy accordingly. Based on the above simulation results, a more detailed simulation can be performed. Thus, under the shift duration of $0.47 \mathrm{~s}$, the peak value of speed fluctuation is approximately $692 \mathrm{rad} / \mathrm{s}$, with an overshoot of approximately $10.2 \%$. Under the shift duration of $0.99 \mathrm{~s}$, the peak value of speed fluctuation is approximately $661 \mathrm{rad} / \mathrm{s}$, with an overshoot of approximately $5.3 \%$. According to the simulation results, when the shift time is not less than $0.47 \mathrm{~s}$, the overshoot is less than $10 \%$. When the shift duration is not less than $0.99 \mathrm{~s}$, the overshoot is less than $5 \%$.

\subsection{Influence of Internal Excitation on the Dynamic Response.} From the dynamic model based on the bond graph, it can be deduced that the coefficients in differential and algebraic equations will influence the motion state of each part, i.e., the rotating speed and torque at each node. According to the physical significance, the torsional stiffness, rotational damping, and moment of inertia of the gear and shaft in the system should be considered. The control variable method is adopted to analyze the influence of a certain factor on the dynamic characteristics of a double-planetary transmission system.

5.3.1. Effect of Damping. The internal damping of the system can be altered by adding the damping ring structure in the gear system, changing the material of the internal structure, and optimizing the internal structure of the gear, shaft, and housing. With other parameters in the model remaining constant, the rotational damping of the system is adjusted to 0.5 or 2 times the preset value. Numerical simulation is conducted to obtain the time-domain curve of the main parts of the system, as well as the rotating speed curves of the output shaft; in addition, the planetary pinion is illustrated in Figures 10 and 11, respectively.

Figures 10 and 11 demonstrate that in a steady state, the rotating speeds of the output shaft are approximately $314 \mathrm{rad} / \mathrm{s}$ and $628 \mathrm{rad} / \mathrm{s}$ in the low and high gear states, respectively. In addition, the rotating speed of the planetary gear is approximately $1785 \mathrm{rad} / \mathrm{s}$ in the low gear state, and it is reduced to zero in the high gear state, which is consistent with the functional requirements of the gearbox. After launching and upshifting, the rotating speeds of the output shaft and planetary gear both reach a stable state after a vibration period. With the increase in rotational damping, the vibration durations for the rotating speeds of the output 


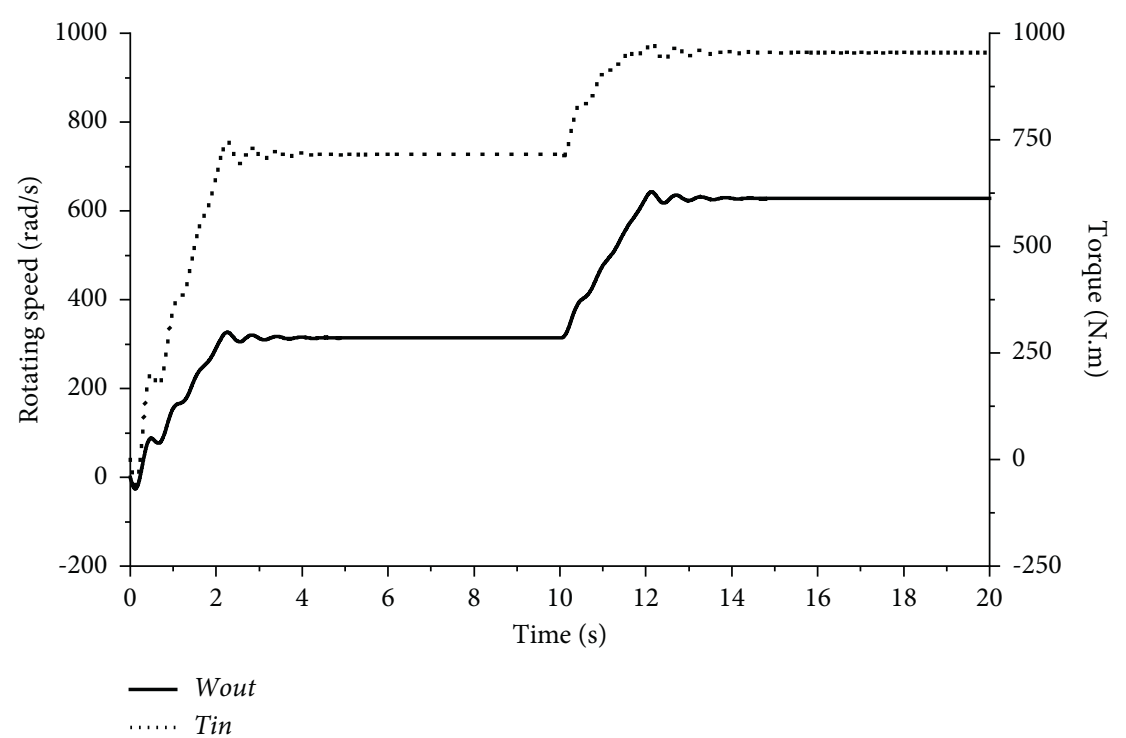

(a)

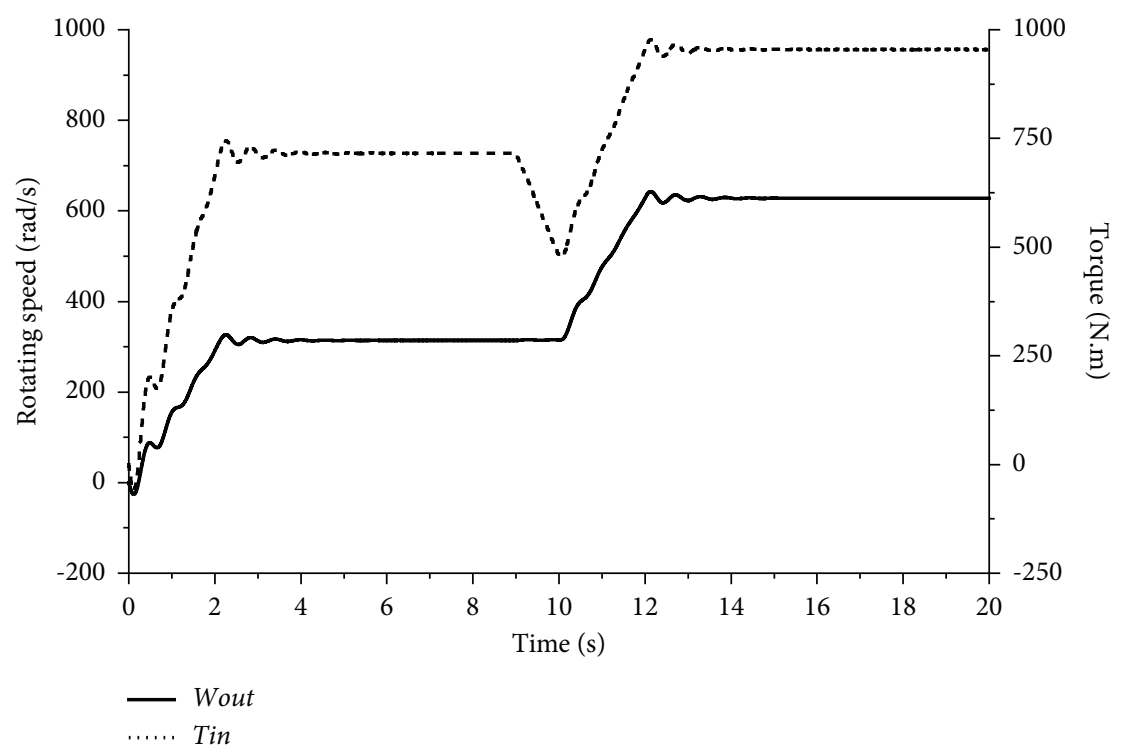

(b)

Figure 7: Output speed and input torque curves. (a) Scheme A. (b) Scheme B.

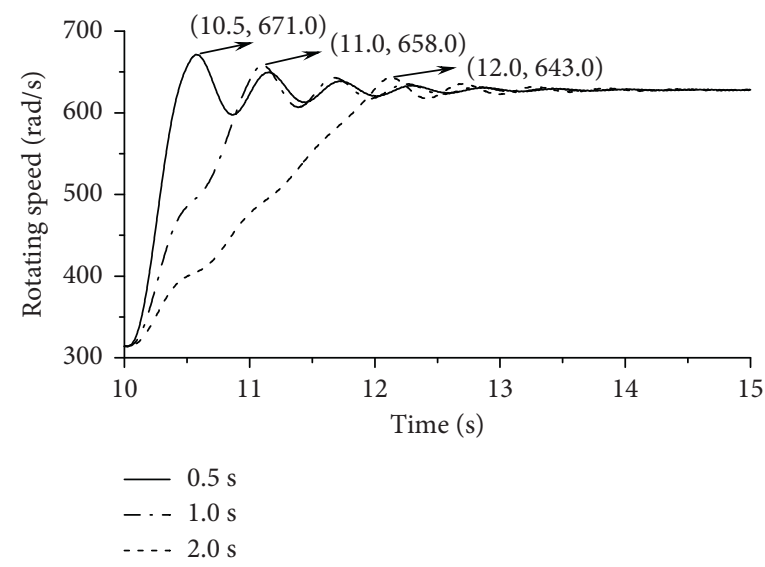

Figure 8: Output speed curve under different shift times. 


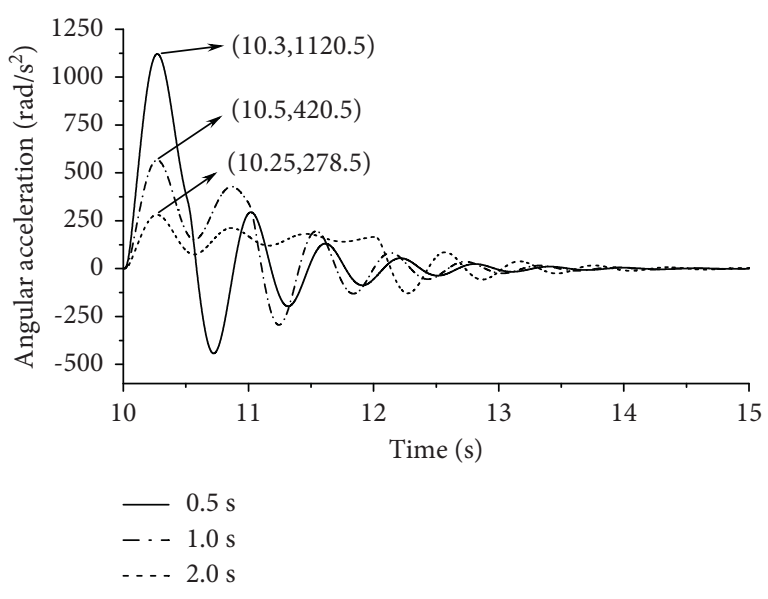

FIGURE 9: Output acceleration curve under different shift times.

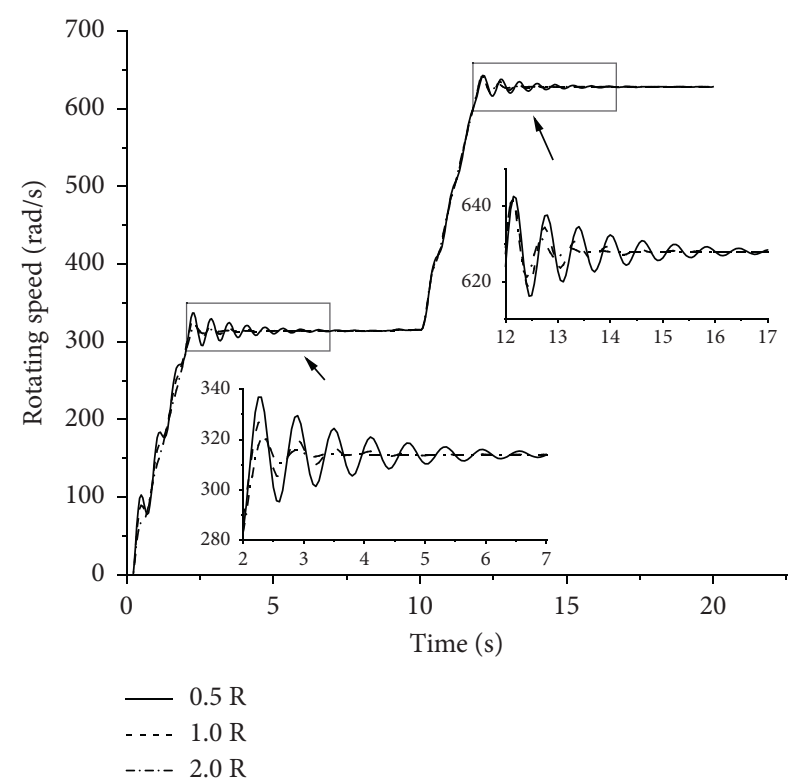

FIGURE 10: Rotating speed curves of output shaft under different damping conditions.

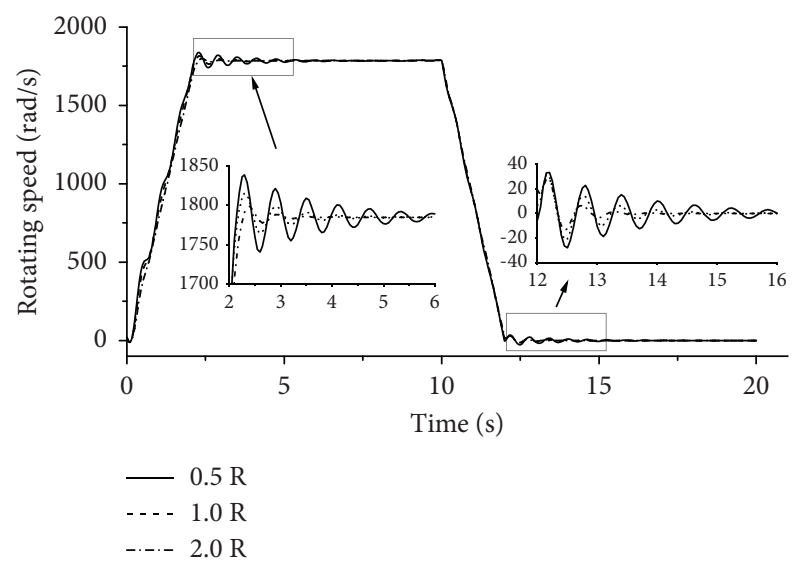

FIGURE 11: Rotating speed curves of planetary pinion under different damping conditions. shaft and planetary gear decrease, the vibration period is prolonged, and the vibration amplitude is significantly reduced. When the damping is reduced, the time taken by the output shaft and planetary gears to reach a steady state increases, the vibration period is shortened, and the amplitude of the rotational speed vibration increases. Therefore, increasing the damping appropriately can make the rotating speed more stable; however, if damping is excessively high, the transmission efficiency of the gearbox is reduced, thereby reducing the endurance and fuel economy of the vehicle. Practical lubrication methods can ensure that the internal damping of the system remains in the appropriate range, to guarantee the speed stability of the gearbox components, including the stability of the system.

5.3.2. Effect of Stiffness. In the gear train, the structure of the gear web, material of the gear, and presence of a damping ring all influence the gear meshing stiffness. The gear profile modification influences the stiffness less significantly than the other three factors. Under the condition that the other parameters in the model remain constant, the stiffness of each part of the system is adjusted to 0.5 or 2 times the preset value. The time-domain curve of the rotating speed of the main parts of the system is obtained via numerical simulation. The rotating speed curves of the output shaft and planetary pinion are presented in Figures 12 and 13, respectively.

Figures 12 and 13 depict that after launching and upshifting, the rotating speeds of the output shaft and planetary pinion reach a stable state after a short vibration period. With the increase in the internal meshing and torsional stiffnesses of the system, the vibration period of the rotating speeds of the output shaft and planetary pinion increases, the rotating speed reaches a stable state faster, and the vibration amplitude is significantly lower. However, when the stiffness decreases, the rotational speed reaches a stable state. With the increase in the steady-state time, the vibration period is shortened, and the amplitude of the speed vibration increases. Therefore, a practical and safe design range can be observed when the gearbox can respond quickly and reach a stable state under external excitation by improving the stiffness of the system. Using high elastic modulus materials, increasing the strength of parts via production processes, shortening the shaft length, increasing the shaft section area, adding ribs, and increasing the thickness of the gear spokes and flanges can all improve the rigidity of the system.

5.3.3. Effect of Moment of Inertia. Keeping other parameters in the model constant, the moment of inertia of the main parts of the system is adjusted to 0.5 or 2 times the preset value. The time-domain curves of the rotating speed of the system's main parts are obtained via numerical simulation. The rotating speed curves of the output shaft and planetary pinion are presented in Figures 14 and 15, respectively.

Figures 14 and 15 show that in the launching and upshifting processes, as the moments of inertia of the main parts increase, the durations of the rotating speed vibrations 


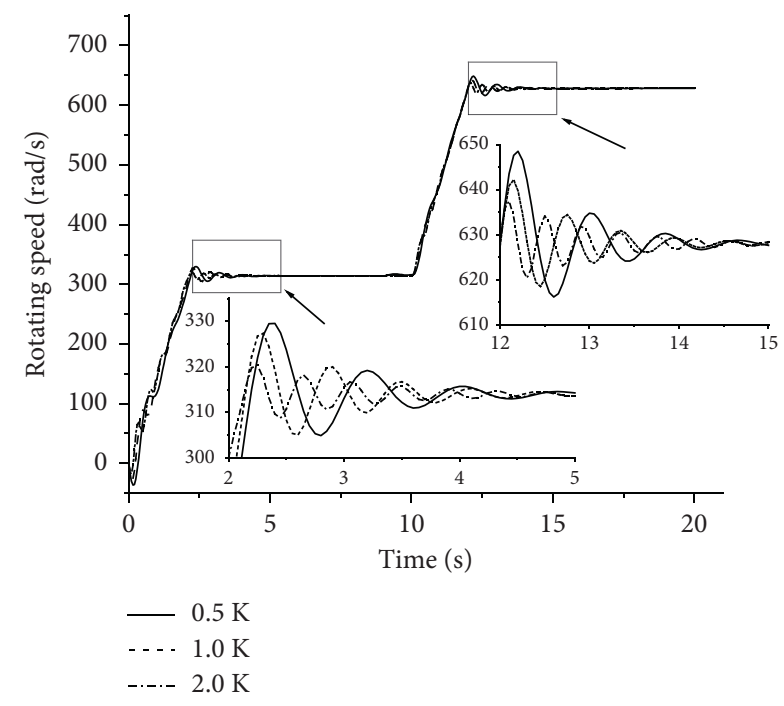

FIGURE 12: Rotating speed curves of output shaft under different stiffness conditions.

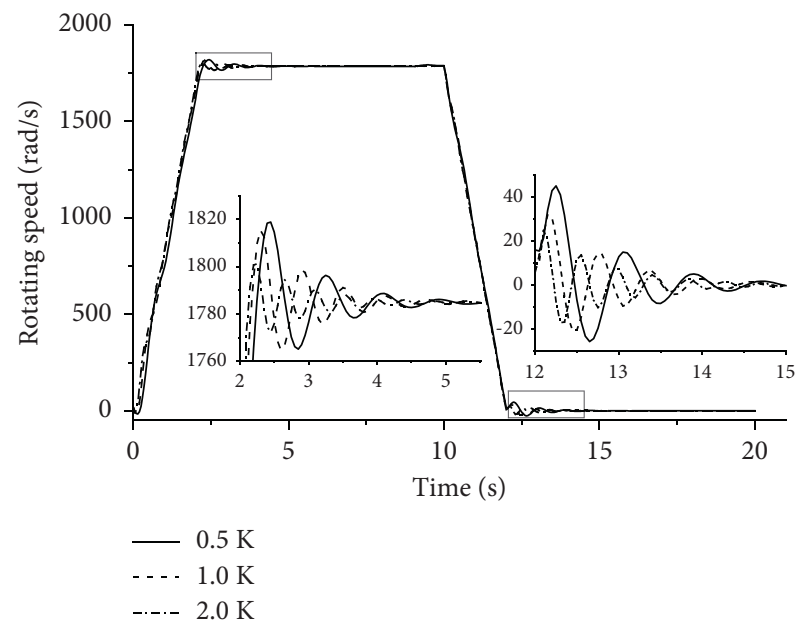

FIGURE 13: Rotating speed curves of planetary pinion under different stiffness conditions.

for the output shaft and planetary pinion increase, and the amplitudes of the these vibrations increase significantly. When the moment of inertia decreases, the time required for the rotating speed of the output shaft and planetary pinion to reach a steady state is shortened, and the amplitude of the rotating speed vibration reduces. Therefore, within a certain range of influence, the strength of the parts must be ensured while using low-density materials. To improve the transmission performance of the gearbox, the configuration of the parts should be optimized to reduce the moment of inertia of the parts.

However, there is a trade-off between reducing the moment of inertia of the parts and increasing the stiffness of the system. Although the method for reducing the mass can effectively reduce the moment of inertia, it will reduce the comprehensive stiffness of the system. From the previous section, it can be inferred that the reduction of the comprehensive stiffness is unsuitable for the fast response and

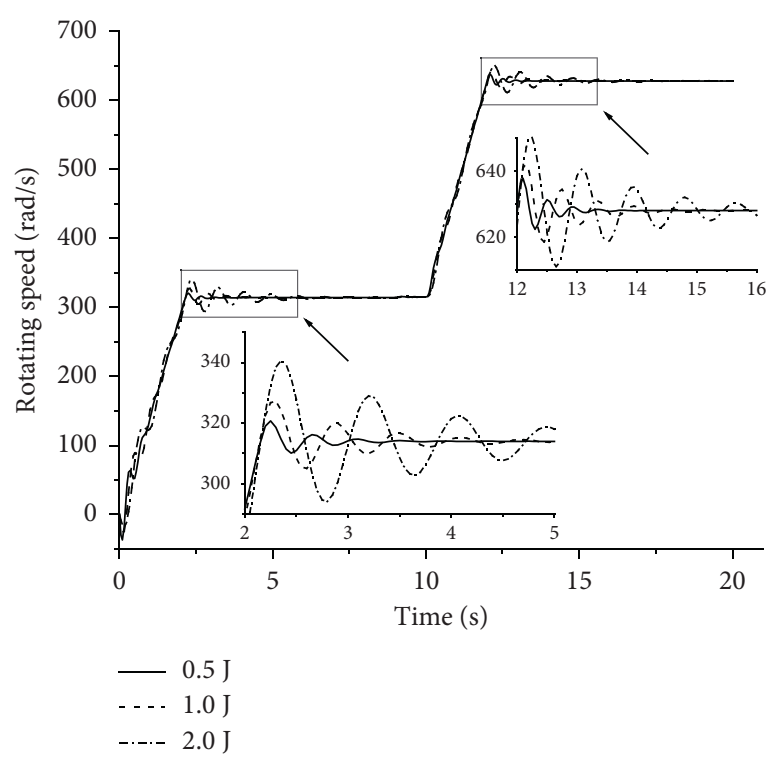

FIGURE 14: Rotating speed curves of output shaft under different moments of inertia.

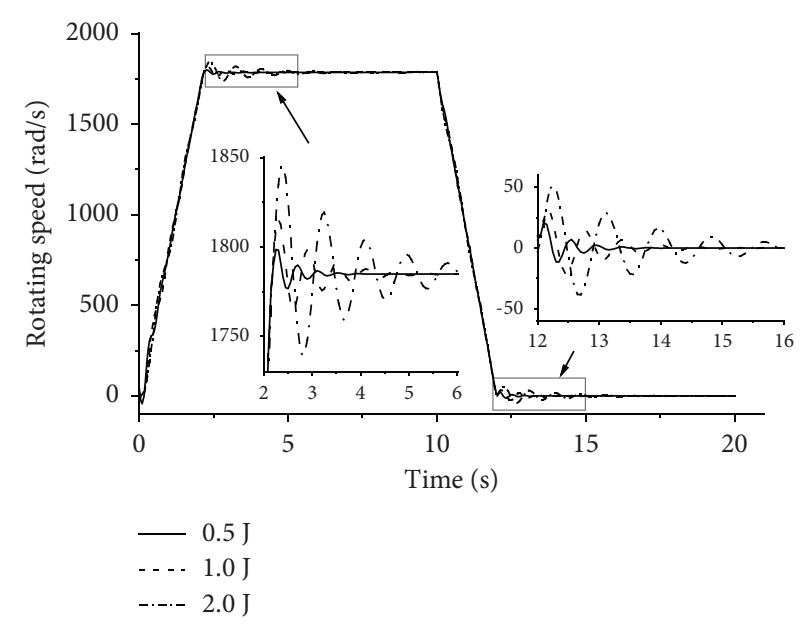

FIGURE 15: Rotating speed curves of planetary pinion under different moments of inertia.

stable operation of the system. Therefore, it is necessary to conduct a comprehensive evaluation on the influence of different factors and develop a multi-parameter collaborative optimization design based on the optimization goal.

\section{Summary and Conclusion}

In this study, two shift modes were adopted to analyze the relationship between motor power and output torque, and shift schemes were evaluated for different control strategies. The influence of shift duration on output speed response was investigated. It can be inferred that the shorter the upshift time, the higher the amplitudes of output speed and acceleration, as well as the vibration frequency. In contrast, the speed and acceleration curve tends to be stable, which is more conducive to the stability of the system. The analysis results provide indications and suggestions for improving 
the optimal design and control strategy of the doubleplanetary gearbox to achieve the best shift quality. When the overshoot does not exceed $10 \%$, the shift duration is required to be equal to or greater than $0.47 \mathrm{~s}$; when the overshoot does not exceed 5\%, the shift duration is required to be equal to or greater than $0.99 \mathrm{~s}$. The torque of the friction clutch directly affects the engagement time, and the coefficient of friction directly influences the friction torque. Therefore, the change in the coefficient of friction will significantly impact the output speed vibration in the shift process. Hence, it is suggested that in the design process of control strategy, the friction plate's coefficient of friction and the design of the lubrication system should be deeply and carefully analyzed; in addition, the balance between impact and sliding wear should be achieved to obtain a smooth shift control curve. The influence of damping, stiffness, and moment of inertia on the dynamic response of the gearbox was analyzed by the control variable method. The simulation data and curves indicate that the dynamic characteristics of the gearbox can be optimized by increasing the stiffness and damping and reducing the moment of inertia of the parts; however, a mutually exclusive relationship exists between stiffness and moment of inertia.

\section{List of symbols}

$\begin{array}{ll}S: & \text { Sun gear } \\ P 1: & \text { Planetary gear } \\ P 2: & \text { Planetary pinion } \\ C: & \text { Carrier } \\ R: & \text { Ring gear } \\ r_{s}: & \text { Base circle radius of sun gear } \\ r_{p 1}: & \text { Base circle radius of planetary gear } \\ r_{p 2}: & \text { Base circle radius of planetary pinion } \\ r_{r}: & \text { Base circle radius of ring gear } \\ \omega_{s}: & \text { Rotating speeds of sun gear } \\ \omega_{p 1}: & \text { Rotating speeds of planetary gear } \\ \omega_{p 2}: & \text { Rotating speeds of planetary pinion } \\ \omega_{c}: & \text { Rotating speeds of carrier } \\ \omega_{r}: & \text { Rotating speeds of ring gear } \\ \beta_{3}: & \text { Characteristic parameter of planetary gear train } \\ m_{:}: & \text {Module } \\ N_{s}: & \text { Number of sun gear teeth } \\ N_{p 1}: & \text { Number of planetary gear teeth } \\ N_{p 2}: & \text { Number of planetary pinion teeth } \\ N_{r}: & \text { Number of ring teeth } \\ I_{s}: & \text { Moment of inertia of sun gear } \\ I_{p 1}: & \text { Moment of inertia of planetary gear } \\ I_{p 2}: & \text { Moment of inertia of planetary pinion } \\ I_{r}: & \text { Moment of inertia of ring } \\ I_{c}: & \text { Moment of inertia of carrier } \\ I_{\mathrm{out}}: & \text { Moment of inertia at output } \\ S_{f}: & \text { Input speed } \\ S_{e}: & \text { Load torque } \\ k_{m}: & \text { Meshing stiffness } \\ \varepsilon_{\alpha}: & \text { Transverse contact ratio } \\ K_{g}: & \text { Torsional stiffness of gear } \\ C_{g}: & \text { Rotational damping of gear } \\ K_{\mathrm{in}}: & \text { Torsional stiffness of input shaft } \\ & \end{array}$

$K_{\text {out }}$ : Torsional stiffness of output shaft

$\tau_{A}: \quad$ Torque of friction clutch

$K_{f}$ : Penalty coefficient

$\tau$ : $\quad$ Constant time

$\tau_{B}: \quad$ Torque of one-way clutch

$K_{o}$ : Torsional stiffness of one-way clutch

$C_{o}$ : Rotational damping of one-way clutch.

\section{Data Availability}

All data, models, and codes generated or used during the study are included within the article.

\section{Conflicts of Interest}

The authors declare that there are no conflicts of interest regarding the publication of this paper.

\section{Acknowledgments}

This study was supported by the National Natural Science Foundation of China (grant no. 52075552).

\section{References}

[1] G. Boukettaya, O. Naifar, and A. Ouali, "A vector control of a cascaded doubly fed induction generator for a wind energy conversion system," in Proceedings of the 2014 11th International Multi-Conference on Systems, Signals of Devices (SSD), February 2014.

[2] O. Naifar, G. Boukettaya, A. Oualha, and A. Ouali, "A comparative study between a high-gain interconnected observer and an adaptive observer applied to IM-based WECS," The European Physical Journal Plus, vol. 130, no. 5, 2015.

[3] O. Naifar, G. Boukettaya, and A. Ouali, "Robust software sensor with online estimation of stator resistance applied to WECS using IM," International Journal of Advanced Manufacturing Technology, vol. 84, pp. 885-894, 2015.

[4] V. Ranogajec and J. Deur, "An automated model-order reduction method for automatic transmissions," Journal of Dynamic Systems, Measurement, and Control, vol. 139, no. 7, 2017.

[5] J. J. Hu, W. Zhao, Y. Han, Z. Hu, and Y. Zheng, "Power flow and efficiency analyses of dual planetary coupling mechanism based on bond graph theory," Journal of Advanced Mechanical Design, Systems, and Manufacturing, vol. 12, no. 2, 2018.

[6] W. Zhongshuang and J. Weike, "Kineto-static analysis of planetary gear train based on vector bond graph method," Journal of Mechanical Transmission, vol. 5, 2016.

[7] C. Lin, C. Huang, and Z. Cai, "Bond graph model and simulation of coaxial dual-output reducer," Journal of South China University of Technology (Natural Science), vol. 44, no. 7, pp. 34-40+54, 2016.

[8] X. Li and A. Wang, "A modularization method of dynamic system modeling for multiple planetary gear trains transmission gearbox," Mechanism and Machine Theory, vol. 136, pp. 162-177, 2019.

[9] Q. Liang, P. Zheng, and W. Zhao, "Research of dynamic characteristic of RV reducer based on bond graph theory," Journal of Mechanical Transmission, vol. 44, no. 06, pp. 32-36, 2020. 
[10] M. A. Stevens, R. F. Handschuh, and D. G. Lewicki, "Variable/ multispeed rotorcraft drive system concepts," Technical report NASA TM-2009-215456, 2009.

[11] M. A. Stevens, R. F. Handschuh, and D. G. Lewicki, "Concepts for variable/multi speed rotorcraft drive system," Annual Forum Proceedings-American Helicopter Society, vol. 64, no. 3, p. 2440, 2008.

[12] P. X. Palcic, T. Garcia, and Y. Gmirya, "Variable speed transmission for a rotary wing aircraft," US Patent US72967767B2, 2007.

[13] Z. B. Saribay, Analytical Investigation of the Pericyclic Variable-Speed Transmission System for Helicopter Main-Gearbox, $\mathrm{PhD}$ Dissertation, The Pennsylvania State University, State College, PA, USA, 2009.

[14] S. Dridi, I. B. Salem, and L. El Amraoui, "A multi-energetic modeling approach based on bond graph applied to in-wheelmotor drive system," International Journal of Advanced Computer Science and Applications, vol. 9, no. 10, pp. 422-429, 2018.

[15] M. Mosadegh, M. M. Jalili, and A. Mazidi, “A bond graph model for simulating the effects of regenerative braking system on emission of a hybrid vehicle," Proceedings of the Institution of Mechanical Engineers-Part K: Journal of MultiBody Dynamics, vol. 232, no. 4, pp. 481-500, 2018.

[16] I. Dif, A. Kouzou, K. Benmahammed, and A. Hafaifa, "Trajectory tracking control design of a mass-damping-spring system with uncertainty using the bond graph approach," Engineering, Technology \& Applied Science Research, vol. 10, no. 6 , pp. 6427-6431, 2020.

[17] G. Mkadara, J.-C. Maré, and G. Paulmann, "Methodology for model architecting and failure simulation supported by bondgraphs-application to helicopter axial piston pump," Sustainability, vol. 13, no. 4, p. 1863, 2021.

[18] S. Kumar, K. Dasgupta, and S. K. Ghoshal, "Fault diagnosis and prognosis of a hydro-motor drive system using priority valve," Journal of the Brazilian Society of Mechanical Sciences and Engineering, vol. 41, no. 2, p. 77, 2019.

[19] P. Luca, A. Reatti, F. Corti, and R. A. Mastromauro, "Inductive power transfer: through a bond graph analogy, an innovative modal approach," in Proceedings of the IEEE International Conference on Environment \& Electrical Engineering \& IEEE Industrial \& Commercial Power Systems Europe IEEE, pp. 1-6, Milan, Italy, June 2017.

[20] A. Naeem, N. Irshad, and T. Qaisar, "Bond graph modeling of an anthropomorphic prosthetic hand," in Proceedings of the 2016 19th International Multi-Topic Conference (INMIC), pp. 1-7, IEEE, Islamabad, Pakistan, December 2016.

[21] G. Kouroussis, P. Dehombreux, and O. Verlinden, "Vehicle and powertrain dynamics analysis with an automatic gearbox," Mechanism and Machine Theory, vol. 83, pp. 109-124, 2015. 